\title{
Production Metrics for Planning Structural Drafting Operations for Reinforced Concrete Staircases in Structural Firms within Uganda
}

\author{
Vanessa Asiimwe Sheilla Mukonyezi Patience Akugizibwe Ronald Ekyalimpa* \\ College of Engineering, Art, Design, and Technology, School of the Built Environment, Makerere University, \\ PO box 7062, Kampala, Uganda
}

\begin{abstract}
Productivity and production rate benchmarks for labor and equipment in the construction sector are vital metrics used to support comprehensive project planning and control activities. Scheduling and budgeting are the two project planning processes that utilize these metrics in their development and use. There is a misconception that project planning and control processes are mainly undertaken by the contractors for construction process but not by consultants for their analysis, design, and drafting processes. Interactions with practitioners serving in supervisory roles in consulting firms so the need and desire to perform these operations too, so that they are furnished with timeline and cost information to better plan and manage their tasks. However, most research activity has been directed towards obtaining benchmarks related to onsite construction processes leaving those in analysis, design, and drafting clueless about what possible benchmarks for their activities are. This study set out to measure and benchmark structural drafting operations for reinforced concrete staircases. Time measurements were done for two of the different types of reinforced concrete staircase configurations, i.e. straight-run and spiral staircases and benchmarks proposed for each of those types.
\end{abstract}

Keywords: Productivity, production rate, benchmarks, reinforced concrete staircases, structural drafting

DOI: $10.7176 / \mathrm{CER} / 12-5-02$

Publication date:May $31^{\text {st }} 2020$

\section{Introduction}

It is common for developers to run out of ground space to host their infrastructure, especially within urban or semiurban locations, particularly within the building construction industry. When this occurs, planners and designers often opt to expand their structures in a vertical direction resulting in mid-height or tall multi-storey structures, and at times skyscrapers. This option that provides designers/planners with flexibility within the vertical direction always comes with new building component/facility requirements. Buildings that are constructed with facilities above the ground need to have provisions for the occupants and caretakers to move from the ground level to floors above the ground and back. In addition, they need to move other items such as their food, belongings, and waste. Staircases, elevators, and escalators are the typical building components provided to address this need. Elevators and escalators are electrically powered components that make vertical movements between building floors fast and easy. These have the disadvantage of high operating and maintenance costs compared to staircases. Staircases, on the other hand, are reliable and available regardless of power outages or emergencies like fire breakouts. It has also been reported that staircase users reap health benefits from their use. Staircases also contribute to the structural strength of a building by providing resistance to lateral loads such as wind and earthquakes.

The design, detailing, and installation of elevators and escalators are often left to the supplier of these components, who are almost always specialists. However, the design and detailing of staircases is the responsibility of the Structural Engineer that designs the building. Timber, steel or reinforced concrete, are often specified by the design as materials to use in the construction of staircases. However, reinforced concrete is the most commonly used of the three, because of its superior fire-resisting properties. The reinforced concrete stairs are constructed from steel rebar that is embedded within concrete. The size/form and compressive strength are the two parameters used to specify the concrete. Rebar are specified using their diameter and yield strength. The set-up of the rebar within the concrete, and the shape of the concrete, are specified in design drawings. In these drawings, an outline is made that demarcates the boundaries of the concrete envelop and shows the layout of the staircase. This is done in both plan and elevation views. Rebar is then drawn within this outline at the appropriate location and spacing. The different layout shapes used are a function of the space that is available to fit the stairs, the usage of the building, and aesthetics.

Design is a process through which specifications related to the structural strength of infrastructure are developed so that a structurally sound facility can be constructed. This involves the conceptualization of the way that the structure is to behave (the loads, schematic of the structure, free body diagram, etc.), analyzing the structure for kinematic and internal forces resulting from the load excitation. The response of the structure is then utilized to size the structural element, prescribe a strength grade and other constituents such as the size and number of rebars in the case of reinforced concrete. Once this is done, drawings are made, labels added that include design 
specifications. This last process is referred to as drafting. The idealization/conceptualization and analysis are tasks typically performed by Engineers. The drafting is sometimes done by Engineers but in typical situations is done by technicians, referred to as "drafters" in industry. These drafters either utilize hand tools to produce drawings or make use of Computer Aided Drawing (CAD) software to generate drawings on the computer.

Planning (creation of schedules and budgets) and design are frontend processes that are an integral part of the whole construction project. Consequently, they affect the overall project budget and schedule. As such, there is a need for these to be scheduled and budgeted in the same manner that traditional construction activities are handled. However, practitioners tasked with this make use of their gut and experience because there are no documented benchmarks for these frontend activities. Their estimates are often very poor and result in cost and schedule overruns which frustrate the owners of these projects and those tasked with implementing them. The study presented in this paper sought to address this challenge but for one building element - reinforced staircases. Time measurements were done for different activities involved in structural drafting of the different types of staircases that are commonly used, for purposes of generating benchmarks that can subsequently be used to improve the quality of planning (i.e. budgeting and scheduling) for frontend activities, i.e., structural drafting.

\section{Literature Review}

\subsection{Staircases}

In ancient times, buildings were made up of only one storey but it was later realized that the area above the ground level could be utilized to increase the amount of space a structure can offer especially due to the land limitations in urban areas. The advent of storeyed buildings also made way for other building component inventions such as elevators, escalators, and staircases that provided a way to move between different levels in such buildings (Campbell et al 2014). Staircases are the main focus of this study. The primary purpose of a staircase is to provide access from one-floor level to another in high rise buildings. However, staircases also act as the first line of seismic defense and are the primary structural members that consume energy during earthquakes (Jiang et al 2012). They, therefore, increase the structural integrity of a building. Staircases also act as fire escape routes for building occupants in situations that there are fire outbreaks. Staircases may be constructed using timber, metal (steel), or reinforced concrete. This study will be focusing on staircases constructed using reinforced concrete. These can be cast in-situ or pre-cast (Seeley 1986).

Reinforced concrete stairs are widely used for residential and commercial purposes because they are fireresistant, strongest as compared to all, have high tension carrying capacity, and are very durable. They can also be molded into various shapes using formwork resulting in ornamental designs. They can be formed using beams acting as strings with the steps spanning between them, but the more common arrangement consists of a reinforced concrete slab with projections forming the steps. Curbs may be formed in situ with the stairs to receive balustrades. The steps may be finished with granolithic (cement and granite chippings) or terrazzo (cement and marble chippings) placed in position after the concrete has set.

Staircases are comprised of various parts. At a high-level, a staircase is comprised of a flight of steps and landings. Landings are horizontal slab-like components that are located either at the beginning or, at the end of a fleet of steps. The flight of steps is an inclined component that connected two landings (Akin-Adamu 2018). Steps are comprised of a vertical part referred to as a riser and a horizontal part referred to as a going or tread. The rise typically ranges from 155 to $220 \mathrm{~mm}$ while the going ranges from 220 to $340 \mathrm{~mm}$. Once selected, dimensions for the riser and going should be kept consistent throughout the flight for safety reasons (Neufert \& Neufert 2000). The nosing is a term used to refer to the point of intersection between a riser and a going. Building regulations limit the total number of steps to 16 between two successive landings. The waist is the part underneath the step (rise and going) that houses the reinforcement in reinforced concrete staircases. A landing facilitates a change in direction along the staircase and also enables users to rest between the flights. The inclination of a flight of staircases, often referred to as a pitch, is important and usually set at a value of $42^{\circ}$. The minimum clear distance between the overhead structures, for example, the ceilings and tread, which allows easy passage of the users even when carrying objects on their heads is known as the headroom and should not be less than $2 \mathrm{~m}$. A string or stringer is a slopping member that supports the steps in the staircase while the newel post is the vertical member placed at the end of flights. It connects the end of the strings to the handrails. The baluster is the vertical member made of wood or metal that supports the handrail and a row of balusters is referred to as a balustrade. The handrail is the wood or metal member that connects two newel posts and is fixed on top of the balustrade to provide support to the stair climber. Most medieval stairs had no handrail at all as the curvature of the staircase and the proximity of the wall lessened the risk of injury in a fall (Campbell et al 2014). However, the handrail later became essential after the invention of the open well stairs to prevent users from falling down the well. The soffit is the portion underside of the stairs while winders are steps that are narrower on one side than the other and are used to change direction on the stairs without landings. Figure 1 shows the details of the components of a staircase that have been discussed. 


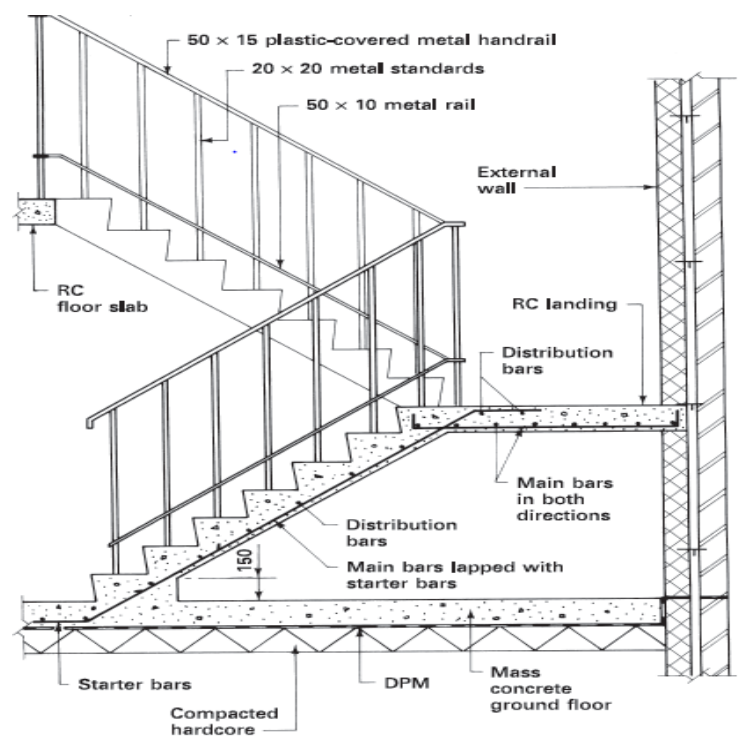

Figure 1. Parts of a Reinforced Concrete Staircase

Staircases can be also classified according to their shapes and geometrical appearances (Chudley \& Greeno 2006). The first type is a straight-run staircase. This type of staircase can have single, double, or triple flights. In the case of a single flight, there is only one flight and two landings. For a double flight, there are three landings and two flights. The number of steps is maintained for both flights. This type of stairs is used when the height of floors is too high and there is enough space to construct. Straight staircases are easy to ascend and descend hence safer for most users. They are also easier to construct due to their simplified configuration as they are connected at the top and bottom and no intermediate support structures are required. However, they are disadvantageous as they use up a fair amount of linear space and this has to be planned for in the design. This reduces the overall efficiency of the building and hence their application is limited to large commercial buildings and workshops due to the amount of space they occupy. The second type is a quarter-turn or L-shaped staircase. This type of staircase changes direction with the introduction of a quarter space landing or by providing winders. They usually have one successive turn and two flights. Each flight makes a right angle to the other. They are usually used when the distance between the floors is less so that adequate height is not obtained for the straight staircases to be provided. They are preferable to straight stairs since they provide a visual barrier between floors hence more privacy. However, they are more difficult to construct than straight stairs. Figure 2 shows the layout of the straight-run and quarter-turn staircases.

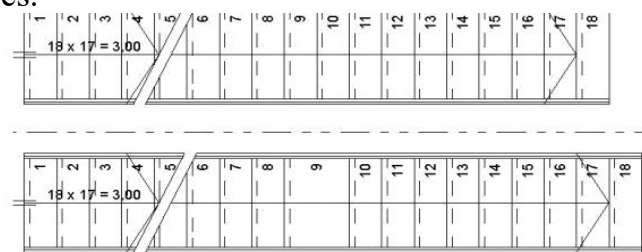

(a)

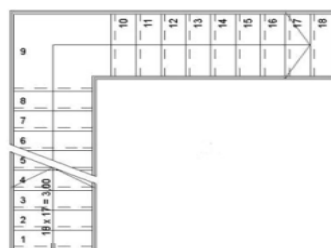

(b)

Figure 2. Layouts of (a) straight-run and (b) quarter turn staircases

The third type of staircase is the half-turn staircase. Half-turn staircases are a type that change direction through $180^{\circ}$. The dogged legged half turn stairs have one newel post at the beginning and at the end of the flight, and there is no gap between the stringers of the flights running opposite to each other. Open newel half-turn stairs differ from the dog-legged staircase due to the presence of a well between the two flights running opposite each other while a geometric half-turn stair is a continuous type of staircase with continuous stringer and handrail where there is no newel post present. There may be a half-space landing or continuous winders. Half-turn stairs are easily fit into most architectural plans, offer privacy to the users and their landings offer a resting point between the flights. The fourth type of staircase is the three-quarter-turn staircase. This type of staircase is used where there is less space for staircases but the height between the floors is very high. In between the two main flights running opposite to each other, there is a small flight normally consisting of three to four steps. Figure 3 shows the layout of the half-turn and three-quarter-turn staircases. 


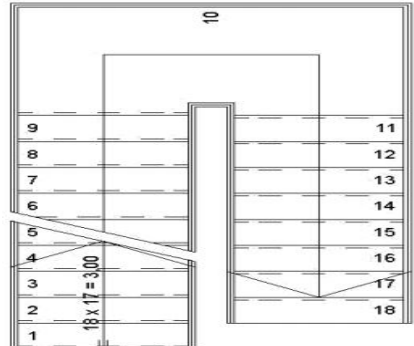

(a)

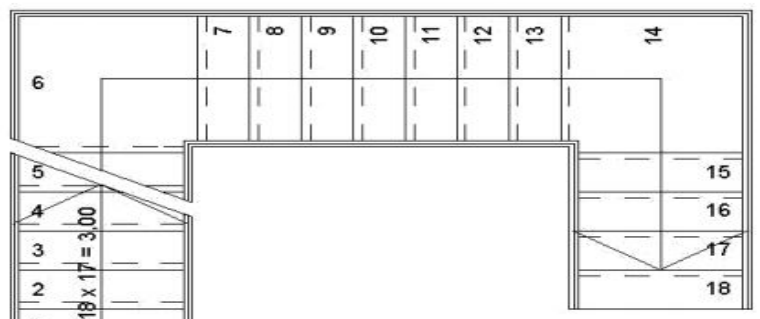

(b)

Figure 3. Layouts of (a) half-turn and (b) three-quarter-turn staircases

The fifth type of staircase is referred to as a bifurcated staircase. Bifurcated staircases are commonly used in public buildings like auditoriums, conference halls, and many others. The wider bottom flights bifurcate into two narrow flights on either side for a better flow of climbers. The sixth type of staircase is referred to as circular or helical or spiral staircases. They are usually used as exit staircases and are located at the back of the building. They are called continuous because they lack landings. Spiral stairs have a plan shape that is generally based on a circle, although it is possible to design an open spiral stairway with an elliptical core. The spiral stairway can be formed around a central large-diameter circular column. Since the center pole and landing provide the support for the stairs, they do not need much in the way of extra support structures hence making installation easier than other types of stairs. They are more difficult to navigate than other types of stairs and cannot. Therefore, be used as the primary access to other floors in residential houses. Curved stairs are continuous with no landing but do not have a common axis of rotation. They are often very elegant and therefore aesthetically pleasing and are also relatively easy to walk up when the radius of the staircase is large. They are far more difficult and costly to build due to the complicated design. Figure 4 shows the layout of the bifurcated and spiral staircases.

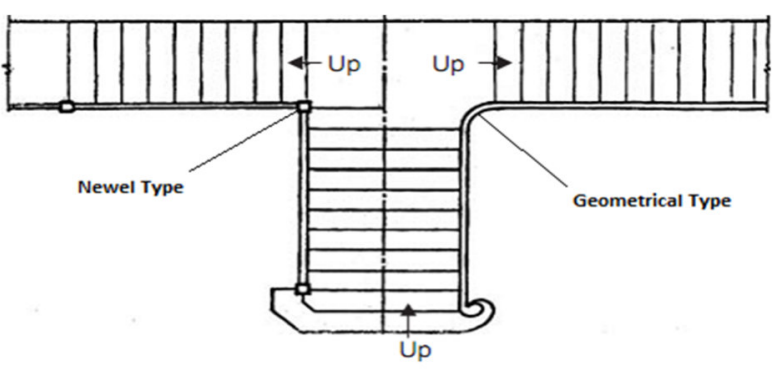

BIFURCATED STAIR CASE

(a)

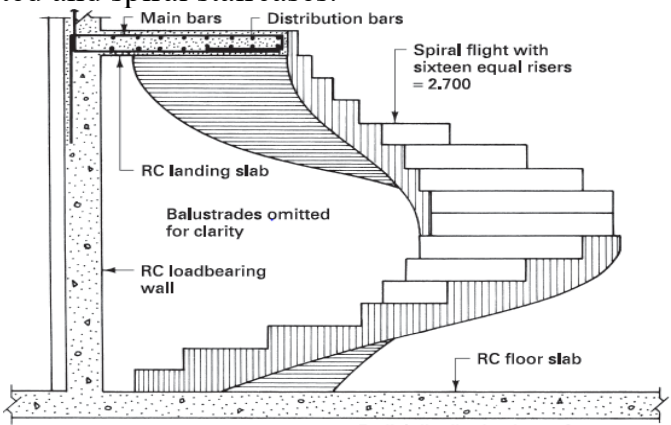

(b)

Figure 1. Layouts of (a) bifurcated and (b) spiral staircases

There are other types of concrete staircases, according to Chudley \& Greeno (2006), which include: stringbeam stairs, cranked-slab stairs, and cantilever stairs. String-beam stairs consist of a string or edge beam used to span from landing to landing to resist the bending moment, with the steps spanning crosswise between them. This usually results in a thinner waist dimension and an overall saving in the concrete volume required, but this saving in the material is usually offset by the extra formwork costs. Cranked-slab stairs are often used as a special feature because the half-space landing has no visible support, being designed as a cantilever slab. Bending, buckling and torsion stresses are induced with this form of design, creating the need for reinforcement to both faces of the landing and slab or waist of the flights. The amount of reinforcement required can sometimes create site problems concerning placing and compacting the concrete. Cantilever stairs, also referred to as spine wall stairs, consist of a central vertical wall from which the flights and half-space landings are cantilevered. The wall provides a degree of fire resistance between the flights, and they are therefore used mainly for escape stairs. Because both flights and landings are cantilevers, the reinforcement is placed in the top of the flight slab and in the upper surface of the landing to counteract the induced negative bending moments. The plan arrangement can be a single straight flight or, as is usual, two equal flights with an intermediate half-space landing between consecutive stair flights (Hassoun \& Al-Manaseer 2015).

\subsection{Production Rate}

Production rate is a very important metric used to appraise the performance of a production system. Another common name used to refer to this metric is throughput. The production rate measures the pace at which the production system is going. Production rate is formally defined as the amount of time within which a system generates a certain quantity of products or services or attains its goals (Investopedia 2016). This definition is expressed mathematically in Equation 1. 


$$
\text { Production rate }=\frac{\text { Quantity or unit produced }}{\text { Time needed to produce unit }}
$$

Production rate measurements often strive to acquire a universally accepted definition of what a unit of product or service is before efforts are directed towards the quantification of the time required to produce that unit. As all this diagnostic work and analysis is being done, there is no regard for effective utilization of resources required to achieve a given throughput. There can be a ramp-up of input resources to levels that are more than optimal and these are expended in order to achieve a particular throughput, hence resulting in lower production system efficiency levels. It is for this reason that scholars regard the production rate as a limited metric for the measurement of performance of production systems and make use of metrics such as productivity rates.

\subsection{Productivity Rate}

The production rate is not concerned with tracking the speed or pace at which a production system is going. This metric, however, is meant to track the effectiveness or efficiency with which input resources are utilized in the production of a unit of product or service. Consequently, productivity looks at optimizing the labor, equipment, materials, money, etc. expended to produce one unit of product or service. Productivity is formally defined as the amount of resources input to produce a unit of product or service. This is summarized mathematically in Equation 2 .

$$
\text { Pr oductivity rate }=\frac{\text { Input resources expended }}{\text { Unit Output }}
$$

Inputs are often expressed as a dollar figure or in terms of man-hours of machine-hours expended. The use of a dollar value is becoming less common because of the effect of inflation on it. Productivity is important to businesses because that efficiency translates into profit growth and sustainability. Productivity rates can be measured at different levels for example at an activity level, plant level, project level, company level, industry level, national level, regional and global level. Likewise, productivity may be viewed from different perspectives, for example, construction, economic, etc. Depending on the perspective that productivity is being assessed and the level, the output and input resources considered could vary significantly. Consequently, it is important to establish these details for the context considered and avoid making relative comparisons of productivity rates for contexts that are different. Tracing, measurement, and improvement of productivity rates become especially important when the cost per unit of each of the input resources required for the production process is high. However, it is worth noting that in developing countries where there is an abundance of cheap labor, efforts and resources directed towards tracking and improving productivity may not be warranted.

It is often recommended to measure, benchmark, and track production rate metrics before moving on to productivity. This is because production rate is a broader and higher-level metric than productivity and hence easier to measure. It is also important to ensure that market demands are fulfilled in a timely fashion prior to focusing on efficiency issues in any production system. These same concepts are directly applicable to the construction industry. Consequently, in this study, the production rate was a preferred choice for a metric to be used in measuring, tracking and comparing the pace at which work for the same building component but with slight variations in certain features, are executed.

\subsection{Time and Motion Studies}

Time and motion studies are often mistaken to be the same thing yet, in fact, they are different in the way that they are implemented and in the use of their results. Time study methods were pioneered by Frederick Winslow Taylor (Krenn 2011) while motion studies were pioneered by Frank and Lillian Gilbreth (Baumgart \& Neuhauser 2009). Today, both methods are said to belong to an integrated work systems approach known as methods engineering. Payne, Youngcourt \& Watrous (2006) state that at the most basic level, time study methods involve breaking down a job into component parts, timing each part, and if necessary rearranging the parts into the most efficient method of working. In time studies, there is a direct and continuous observation of a task and measurement using stopwatches or videotape cameras to track the amount of time needed to complete the task. The technique allows for adjustments in the measured time which account for breaks, delays, fatigue-induced rest periods, personal needs, etc. (Payne et al 2006). Time studies are mainly used to generate time-based benchmarks related to the performance of tasks. The technique can also be used to re-sequence activities to minimize the overall completion time.

Motion studies are said to have been motivated by Taylor's time studies (Baumgart \& Neuhauser 2009). Motion studies involve observing and analyzing the body posture of workers while carrying out their tasks, i.e. work motion. The observation piece is often done by filming/videotaping the workers as they carry out their activities. This creates a visual record of how work is performed which can serve as a basis for two things. First, the visual recordings can serve as a basis for any diagnostic work that may be needed in the identification of areas of work performance that could require improvement. Second, the visual record obtained can be used for purposes 
of training workers on the best way to perform their work, i.e. healthy, safely, and in a timely fashion. Ergonomic aspects deciphered from video footage postures are mainly used to foster the health and welfare of individual workers while they engage in work tasks. Postures and maneuvers performed during work execution can be to understand safety issues related to an individual, crews, and an entire work environment.

From the discussion presented, it can be noted that results from time studies can mainly be applied towards production rate and productivity monitoring and improvements. Motion studies, on the other hand, can feed into numerous aspects such as production rate, productivity, quality, health, and safety, etc. Strictly speaking, it can be said that motion studies seem to have broader applications than time studies. However, both have their place in management science hence cannot do away with either.

\subsection{Work Sampling}

Work sampling is a technique that is used to assess the efficiency with which a certain piece of work is done. Work sampling was initially developed for mainly examining performance in manufacturing environments (Tsai 1996). However, today it is being applied more broadly in healthcare and the construction industry (Buchholz et al 1996; Ampt et al 2007). It involves splitting up a job into various activities or tasks (Sheth 2000; Groover 2007). These tasks serve as work categories. Other things that are regarded as support tasks or as time-wasting and non-value adding activities that workers engage in are added to the main core categories that were generated by breaking down the job (Sheth 2000; Groover 2007). Examples of the additional categories include: setting up tools or equipment/machines, waiting for work, waiting for materials, waiting for instructions or approvals, health breaks, idling, personal breaks, fatigue-induced rest, etc. The essence of work sampling is to determine the percentage of time that a worker spends within each of the categories associated with a job for the time that they are executing the job. Knowledge of this gives analysts and those performing diagnostics insights into areas in which improvements can be made especially if a significant percentage of time is expended on support or non-value adding activities. Another important aspect of work sampling besides generating the job categories relates to the total number of samples that need to be obtained in order to be confident that the process generates a credible result. The sample size computation is based on the choice of standard error, confidence level, etc.

Work sampling is presented here as a productivity and production rate diagnostic technique. Its application in the development and updating of benchmarks for these performance metrics is extremely limited. As such, this technique was not utilized in this study although it is an extremely powerful and useful technique.

\subsection{Benchmarking}

Benchmarking is such a popular phenomenon these days especially with the business world because it gives insights into how well or badly operations and processes are doing. There are several books released which cover the subject of benchmarking with some of the popular ones being published by Boxwell and Robert (1994), and Camp (1989). It is worth noting that the concept of benchmarking is an extremely diverse one and can be used to imply different things depending on the individual and the context in which it is used. One popular use of the term benchmarking is when referring to a metric that has been developed with the intent of it serving as a reference point, gauge, yardstick, etc. Often that reference point is regarded as a standard of excellence, achievement, etc. Also, the quality and quantity of the metric are known. Benching marking can also be used to define any process in which similar entities are compared using a reference point, gauge, yardstick, or measure. Benchmarking is used to measure performance basing on indicators such as quality, time, and cost. This is referred to as metric benchmarking. Performance measures developed concerning these indicators include, productivity, cycle length, and the number of defects within a given time or for a specific quantity produced (Fifer 1989). The two most common forms of quantitative analysis used in metric benchmarking are Data Envelopment Analysis (DEA) and regression analysis. DEA technique has the ability to generate an efficient frontier based on many different metrics or indicators and measure various entities based on that.

In the construction industry, there have been initiatives to benchmark projects internally within the company. Examples include studies by Camp (1995), Walker (1996), and Garnett and Pickrell (2000). In most of these instances, reference has been made to Key Performance Indicators (KPIs) and best practices when benchmarking construction processes and projects within companies (Camp, 1995). Benchmarking has not been restricted to the company level only, it has also been used at different other levels. At a more global level, the Construction Industry Institute (CII) has tried to do continuous benchmarking of construction projects for the entire construction industry (Garnett and Pickrell 1995). CII has got its headquarters in the USA and the majority of the projects that they use to develop benchmarks are from within North America. This study intends to generate metrics that can be used in various ways for one aspect of the design of buildings - staircase structural design. The metrics may be used for performance assessment. The metrics may also be used in project planning activities such as budget costing and scheduling. Also, various values are collected for production rate and probability distributions fitted to those as a way of benchmarking. 


\section{Methodology}

This section on methodology provides a description of the research activities that will be undertaken, the resources and techniques that will be utilized in undertaking each of these activities. The nature of the methodology and consequently the research activities will depend on the type of research study being undertaken. The study that was undertaken in this paper was one that required field measurements to be performed alongside interviews. Interviews were conducted so as to gain insight into aspects of interest that could not be directly measured but that practitioners are aware of and have acquired and stored in their brains as formal or informal knowledge. It is often not feasible to study an entire population as it relates to the research. In such cases, it is encouraged to study samples picked from that population utilizing a well-chosen sampling technique. This was the case in this study. It was decided that the population in this study was comprised of civil engineering firms that consult in structural engineering work. This is because its practitioners (i.e. structural engineers) within such firms would be directly responsible for the analysis, design, drafting, and supervision of any staircase elements that may exist within facilities. Although there are cases where structural engineers take on all roles of analysis, design, drafting, and supervision, it is not uncommon to have trained technicians using design outputs from structural engineers and undertake the drafting work. As such all practitioners - structural engineers, structural engineering draftspersons, their supervisors were targeted in this study.

In Uganda, the majority of structural engineering firms are located within the capital city, Kampala. As such, the study was limited to covering only those within Kampala. The structural firms that practice structural design of building facilities as part of their scope of work constituted the population of the study. Both strategic and snowballing sampling techniques were applied to identify the firms to study. The first group of firms was chosen strategically based on the fact that they are well known consulting firms in town and because some of the practitioners within those firms were known to the researchers. The other firms were accessed on the recommendation of those firms that had first been sampled strategically. The authors were able to get access to and conduct their research within these additional firms because practitioners in the initially selected firms personally knew those in the additional one and explicitly sought permission on our behalf. It is worth mentioning that it was difficult to get authorization to study a number of consulting firms over concerns of disclosure of their internal practices which would compromise their competitive advantage. Consequently, the study resolved to limit their research to 10 key structural consulting firms operating within Kampala. A stratified sampling approach was used to select the employees within each selected firm that would be involved in the research study. Structural engineers, technical draftsmen, technical supervisors of these two worker categories. These technical supervisors were to provide information about factors that affect the pace at which drafting is done in the firm, drafting methods used in the firm, etc.

The research was able to study a total of 17 draftsmen (including structural engineers and technicians). Interviews were conducted to determine the methods and tools that they used to complete their drafting work, the factors that affect the rate at which they perform their work, etc. Both draftsmen and their supervisors participated in interviews regarding these issues. In order to maximize the information that was obtained from interviewees, different styles of interviewing were used, namely, formal/structured, semi-structured, and informal/unstructured. The interview style utilized was customized to the type of interviewee, their portfolio, the amount of time that they were willing to commit, etc.

Work measurements were conducted by observing draftsmen as they worked and tracking the amount of time that they took to execute their drafting tasks. Stop clocks were utilized and records were taken in a journal on activity durations. Standard time study protocols and procedures were adhered to during the work measurement process. It is worth noting that prior to tracking durations, observations were done to map out the different tasks undertaken to draft a complete staircase and the sequence in which these tasks are executed mapped out also. Once this was done, time studies were done as elaborated to establish durations taken to complete each task. Multiple measurements were taken for each draftsman and then for multiple draftsmen and all results recorded.

Data that was transferred into MS. Excel files after the work measurement had been completed. Data models were then fitted to the dataset for each activity so that it was in a form that can be utilized in more advanced numeric computation. Probability distributions were the data model chosen and the EasyFit software was used to complete the distribution fitting process. The cycle length associated with completely drafting an entire staircase was computed using a Monte Carlo simulation experiment. The code was written for this experiment within the Mathematica environment. The probability distributions that were fitted to the durations of the different activities were entered as inputs to the Monte Carlo simulation experiments. Output analysis was done on the results generated from the Monte Carlo simulation experiments.

\section{Analysis, Results, and Discussions}

\subsection{Drafting Tools}

The study tried to establish the drafting tools that are in use at the structural engineering consulting firms studied. It was established that none of them make use of manual drafting methods. All draftsmen within all the consulting 
firms were trained in and utilize Computer-Aided (CAD) software for doing their drafting work. Findings revealed that $A u t o C A D$ is the most popularly used drafting software. ArchiCAD was the next popularly used software for its drafting work. One structural consulting firm reported that it makes use of a drafting software referred to as Orion. About $42 \%$ of the structural firms studied indicated that they make use of one type of software in their structural drafting work. The rest utilize only one structural drafting software.

\subsection{Factors Affecting Staircase Structural Drafting}

Like any other operation, structural drafting is an activity or a series of activities that are affected by a set of factors. It was thought that knowledge of these factors would be extremely useful to establish as these could be useful to those in-charge of supervisors' structural drafters. These factors could contribute to the set of tools that supervisors have at their disposal for motivating their crews. Factors were obtained from interviewing the draftsmen, and their supervisors. In the first iteration, respondents were asked to identify all the factors that they felt affect the pace at which drafting work is done. The findings were then analyzed and filtering was done to obtain the six most critical factors. Then respondents were approached once again to determine the ranking of those six factors. Each respondent was asked to rank the factors. These respondents were each given a weight that reflected the importance and reliability of their response. The weighted average rank for each factor was then computed using the following formula (Equation 3).

$$
R_{\text {Average }}=\frac{\sum_{i=1}^{n} W_{i} R_{i}}{\sum_{i=1}^{n} W_{i}}
$$

A three-point ranking scale was used to specify the relative importance of the factors. A value of 1 was assigned if the respondent thought a factor is of least importance or unimportant; a value of 2 was assigned if the respondent thought that a factor is important and then a value of 3 was assigned if the respondent thought a factor is very important. Similarly, a three-point scale was used to attach weights to experts (1-not important opinion, 2important opinion, 3-very important opinion). The factors were then ranked in descending order of the average weighted rank value $\left(\mathrm{R}_{\text {Average }}\right)$ such that the top ranking factors had the largest weighted average rank and the bottom ranking factors had the least. Table 1 summarizes the top six factors that were found to affect structural drafting of staircases ranked in the order of their extent of influence.

Table 1. Ranking of factors influencing staircase structural drafting by relative importance

\begin{tabular}{|c|l|}
\hline Rank & \multicolumn{1}{c|}{ Factors influencing staircase structural drafting } \\
\hline 1 & Competence of the draftsman (Level of education, experience, training) \\
\hline 2 & Type of staircase (staircase layout and construction material used) \\
\hline 3 & Rework (especially from unanticipated changes - induced by architect or owner) \\
\hline 4 & Drafting method and tools (type of CAD software) \\
\hline 5 & $\begin{array}{l}\text { Work environment (air conditioning, quality of work station - computer specs, desk, chair, } \\
\text { presence/absence of noise) }\end{array}$ \\
\hline 6 & Psychological factors (supervisor, client or self-induced pressure, motivation/demotivation) \\
\hline
\end{tabular}

\subsection{Structural Drafting of Staircases}

\subsubsection{Drafting Process}

The first step undertaken in studying the structural drafting of staircases involved abstracting and mapping out the different activities and their sequence in the form of a schematic diagram. This was done through observation of draftsmen at work and interactions with them about the fashion in which they get their work done. The generic schematic layout obtained is summarized in Figure 5.

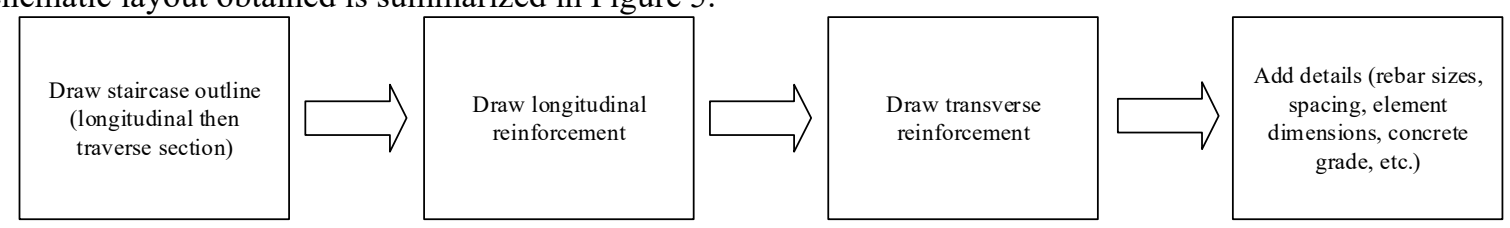

Figure 5. Sequence of activities undertaken when structural drafting staircases

This schematic layout served as the basis for the time measurement that was done. Durations taken by each draftsman to complete each activity was tracked and recorded. This was done when straight-run staircases and spiral staircases were being drafted. The data obtained is summarized in Tables within the following sections.

4.3.2 Straight-run Staircases

The attributes of straight-run staircases in most buildings are generally within close proximity of each other from a dimensions perspective. This is because of the strict building guidelines that have to be adhered to, to ensure that they are safe for use. Data collected was on the drafting of staircase section that connects and two levels of a 
building. This was typically comprised of three landings and two fleets of stairs. Durations in minutes spent drafting such a typical segment of the reinforced concrete staircase were summarized in Table 2.

Table 2. Durations in minutes for structural drafting straight-run reinforced concrete staircases

\begin{tabular}{|c|c|c|c|c|}
\hline Instance & Stair outlining & Longitudinal rebar & Transverse rebar & Detailing \\
\hline S1 & 12.50 & 10.60 & 9.03 & 25.92 \\
\hline S2 & 5.00 & 7.33 & 6.42 & 45.83 \\
\hline S3 & 17.17 & 18.92 & 16.50 & 47.01 \\
\hline S4 & 10.50 & 15.58 & 13.60 & 55.44 \\
\hline S5 & 10.33 & 12.70 & 12.55 & 32.00 \\
\hline S6 & 19.00 & 5.02 & 5.00 & 43.50 \\
\hline S7 & 15.55 & 5.50 & 5.67 & 30.25 \\
\hline S8 & 8.20 & 8.20 & 8.05 & 31.03 \\
\hline S9 & 6.47 & 6.47 & 10.33 & 28.72 \\
\hline S10 & 12.32 & 12.32 & 5.24 & 30.00 \\
\hline S11 & 10.15 & 10.15 & 10.21 & 40.93 \\
\hline S13 & 15.00 & 15.00 & 7.31 & 22.13 \\
\hline S14 & 6.31 & 6.31 & 6.82 & 31.43 \\
\hline S15 & 7.81 & 7.81 & 12.12 & 41.77 \\
\hline S16 & 8.41 & 8.41 & 8.61 & 25.05 \\
\hline S17 & 7.50 & 7.50 & 5.68 & 24.07 \\
\hline
\end{tabular}

4.3.2.1 Straight-run Staircases: Basic Statistics and Input Modeling

The first step in the analysis involved computing basic statistics for the dataset for each structural drafting activity. A code snippet was written in Mathematica software and run to generate values for each statistic. The results obtained are summarized in Table 3.

Table 3. Basic statistics for the duration of activities in drafting of reinforced concrete straight-run staircases

\begin{tabular}{|c|c|c|c|c|}
\hline Statistic & Stair outlining & Longitudinal rebar & Transverse rebar & Detailing \\
\hline Minimum & 5.00 & 5.02 & 5.00 & 15.97 \\
\hline Maximum & 19.00 & 18.92 & 16.50 & 55.44 \\
\hline Mean & 10.75 & 9.90 & 8.76 & 33.59 \\
\hline Standard deviation & 4.02 & 3.90 & 3.35 & 10.46 \\
\hline First quartile (Q1) & 7.73 & 7.12 & 5.78 & 25.70 \\
\hline Median (Q2) & 10.33 & 8.41 & 8.05 & 31.03 \\
\hline Third quartile (Q3) & 13.13 & 12.42 & 10.78 & 42.20 \\
\hline
\end{tabular}

Probability distributions were fitted to each of the datasets for the different activities within the EasyFit software. The distributions that showed the best fit were identified and presented in Table 4.

Table 4. Probability distributions for activities for drafting straight-run reinforced concrete staircase

\begin{tabular}{|l|c|}
\hline \multicolumn{1}{|c|}{ Drafting Activity } & Probability Distribution for Duration [Minutes] \\
\hline Stair outlining & Triangular(4.3027,6.47,21.144) \\
\hline Longitudinal rebar & Triangular(5.02,5.02,20.589) \\
\hline Transverse rebar & Beta $(0.66247,1.2252,5.02,22.704)$ \\
\hline Detailing & Triangular(12.854,28.72,59.906) \\
\hline
\end{tabular}

4.3.2.2 Straight-run Staircases: Cycle Length

A code snippet was written within the Mathematica software for estimating the total cycle length for drafting a straight-run staircase. This code is summarized next. 


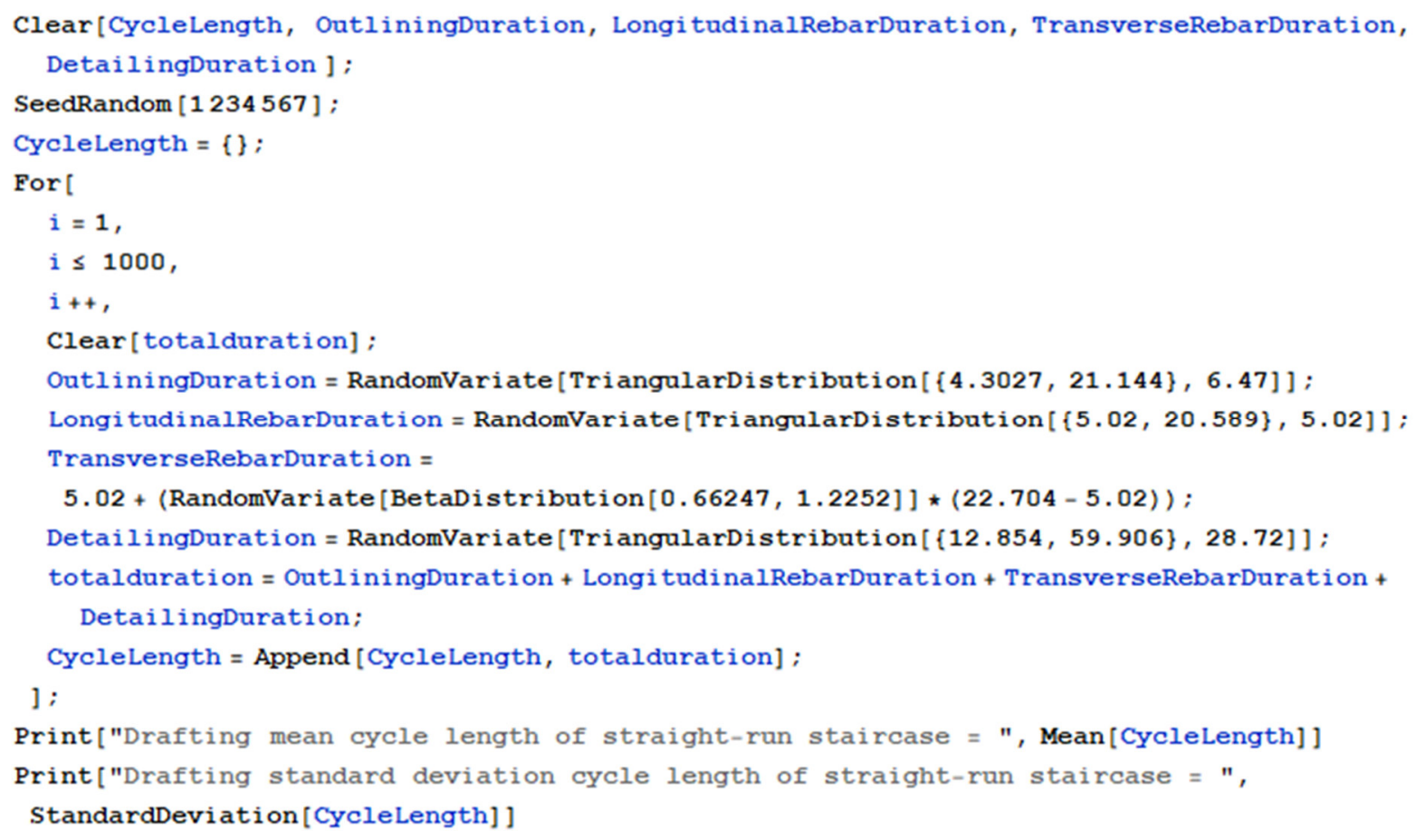

Results from the Monte Carlo simulation indicate that it takes a draftsman an average of 65.40 minutes and a standard deviation of 11.44 minutes to complete structural drafting of a reinforced concrete straight-run staircase using CAD software.

\subsubsection{Spiral Staircases}

A reinforced concrete spiral staircase linking two levels of a building would typically be comprised of a single fleet of stairs and two landings - one at the lower level and another at a higher level. This layout of the spiral staircase was assumed in this study and hence data reports and results obtained from the analysis are in relation to this configuration. The duration values obtained from time studies of draftsmen working on spiral staircases are presented in Table 5.

Table 5. Durations in minutes for structural drafting spiral reinforced concrete staircase

\begin{tabular}{|c|c|c|c|c|}
\hline Instance & Stair outlining & Longitudinal rebar & Transverse rebar & Detailing \\
\hline S1 & 30.00 & 28.43 & 25.55 & 480.77 \\
\hline S2 & 12.22 & 13.34 & 11.55 & 77.00 \\
\hline S3 & 16.60 & 18.32 & 15.42 & 133.75 \\
\hline S4 & 19.00 & 20.32 & 11.54 & 99.56 \\
\hline S5 & 21.22 & 13.00 & 12.65 & 61.50 \\
\hline S6 & 31.41 & 8.93 & 7.35 & 81.25 \\
\hline
\end{tabular}

4.3.3.1 Spiral Staircases: Basic Statistics and Input Modeling

A good point to start when performing analysis that involves numeric data relates to the generation of basic statistics so as to view quick and easy insights into the nature of the data. Mathematica code was used to perform basic statistical analysis on each of the activities and the results obtained are summarized in Table 6.

Table 6. Basic statistics for the duration of activities in drafting of reinforced concrete spiral staircase

\begin{tabular}{|c|c|c|c|c|}
\hline Statistic & Stair outlining & Longitudinal rebar & Transverse rebar & Detailing \\
\hline Minimum & 11.41 & 6.22 & 6.14 & 31.10 \\
\hline Maximum & 31.41 & 28.43 & 25.55 & 480.77 \\
\hline Mean & 20.27 & 15.51 & 12.89 & 137.85 \\
\hline Standard deviation & 7.94 & 7.51 & 6.41 & 154.50 \\
\hline First quartile (Q1) & 13.32 & 9.95 & 8.40 & 65.38 \\
\hline Median (Q2) & 19.00 & 13.34 & 11.55 & 81.25 \\
\hline Third quartile (Q3) & 27.81 & 19.82 & 14.73 & 125.20 \\
\hline
\end{tabular}

Subsequently, probability distributions were fitted to each of the datasets for the different activities within the EasyFit software. The distributions that showed the best fit were identified and presented in Table 7. 
Table 7. Probability distributions for activities for drafting spiral reinforced concrete staircase

\begin{tabular}{|l|c|}
\hline \multicolumn{1}{|c|}{ Drafting Activity } & Probability Distribution for Duration [Minutes] \\
\hline Stair outlining & Beta(0.25074,0.31554,11.41,31.41) \\
\hline Longitudinal rebar & Triangular(6.22,6.22,33.479) \\
\hline Transverse rebar & Triangular(6.14,6.14,29.233) \\
\hline Detailing & Beta(0.04732,0.14023,61.50,480.77) \\
\hline
\end{tabular}

4.3.3.2 Spiral Staircases: Cycle Length

A code snippet was written within the Mathematica software for estimating the total cycle length for drafting a straight-run staircase. This code is summarized next.

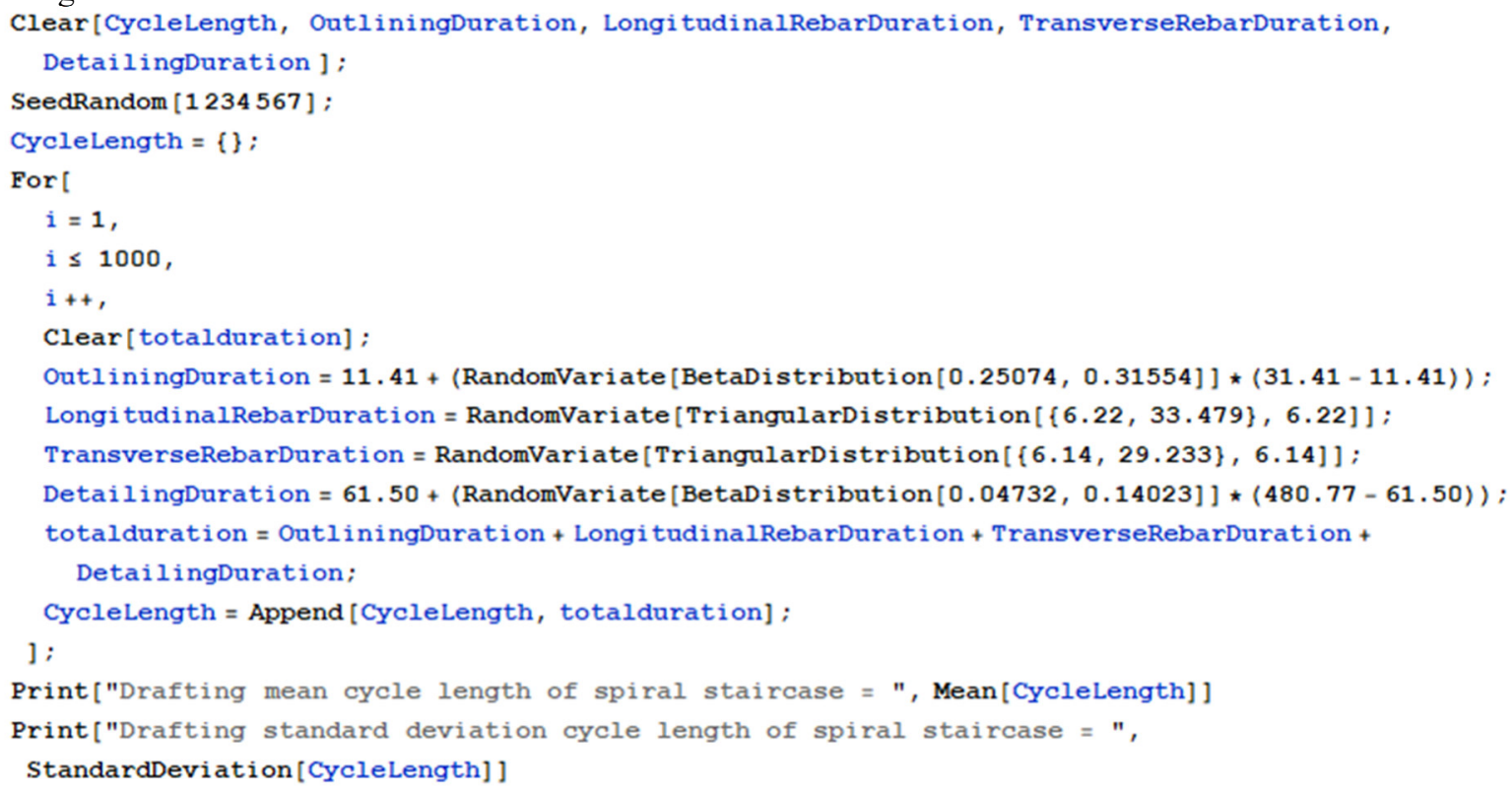

Results from the Monte Carlo simulation indicate that it takes a draftsman an average of 213.38 minutes and a standard deviation of 166.74 minutes to complete the structural drafting of a reinforced concrete spiral staircase using CAD software.

\section{Conclusions and Recommendations}

The extensive use of a multi-storey approach to constructing building infrastructure, whether for residential or commercial purposes has been evident since constrains of space on land became a real issue, particularly in urban settings. This type of building must have staircases as part of its components for serviceability and safety reasons.

Details on specific functions that staircases serve in buildings include, provision of access between different levels of a building. Stairs also provide a safe exit from the building in case the facility is struck by a disaster such as fire, earthquake, etc. When such disasters strike a building, elevators, escalators, and other systems used to access different levels of a building are turned off leaving only staircases as the only option. Stairwell walls and stairs can also serve as shear walls and as structural elements that provide lateral resistance to a building. As such, staircases become a mandatory aspect that needs to be dealt with in structural analysis, design, and drafting given that they are a typical structural element in this type of building facility.

Structural drafting even when using computer-aided design methods is regarded as laborious and time consuming compared with analysis and design activities and hence tends to bottleneck the entire project specification development process. Benchmarking the drafting process was therefore found to be beneficial to the whole front end planning process. Consequently, data was successfully collected from the key structural engineering consulting firms in Kampala, Uganda. This data included durations for executing the different activities in the drafting operation. Data models (continuous probability distributions) were successfully fitted to each of these datasets using the EasyFit software. These probability distributions subsequently served as inputs to Monte Carlo simulations that were written within Mathematica software. These Monte Carlo simulations were used to compute the cycle length for structural drafting each staircase type. Results obtained revealed that it takes an average of 65.40 minutes to complete structural drafting of a reinforced concrete straight-run staircase while it takes an average of 213.38 minutes to complete structural drafting of a reinforced concrete spiral staircase.

It was also established that all the structural consulting firms studied make use of CAD software in their drafting operations. AutoCAD was reported as the most commonly used CAD drafting software. About half of the firms also reported using only one type of CAD software while the other half reported using multiple software in their drafting work. 
It was revealed that the pace at which structural drafting is completed is influenced by a set of different factors just as is the case with any other activity. These factors were related to the draftsman, the tools that they use, and the environment in which they operate. The draftsmen and their supervisors indicated that the most important factor that influences the pace of structural drafting is drafter's competence (education, training, and experience). The next important factor was the drafting tools (software and computer specifications) then factors related to the environment such as the ambiance of the work station and workplace as a whole, the quality of supervision, etc. Knowledge of these factors and their relative importance can serve as a relevant management tool in addressing performance issues of draftsmen in a workplace setting.

In the absence of any other better metrics, it is recommended that those doing planning work for structural drafting make use of the findings of this study when it comes to the staircase building elements if they are to be constructed in reinforced concrete material. The values obtained for straight-run and spiral staircases can be used in the generation of schedules for drafting work and for cost budgeting purposes too. Given that the structural drafting operation is dependent on computer technology to a large extent, there is a need to keep reviewing metric values for these operations, say every 2-5 years given that technology changes at a very fast pace. It is also recommended that similar studies be done for other types of staircases and other structural elements within buildings so that a complete set of metric values that can be used in scheduling and cost estimation of building structural design processes can be obtained.

\section{References}

Akin-Adamu, A. (2018), "Structural Design, Detailing and Construction of Reinforced Concrete Staircases", Young Civil Engineering Forum (YCEF).

Ampt, A., Westbrook, J., Creswick, N., \& Mallock, N. (2007), A comparison of self-reported and observational work sampling techniques for measuring time in nursing tasks. Journal of health services research \& policy, 12(4). DOI: $10.1258 / 135581907779497576$

Baumgart, A. \& Neuhauser, D. (2009), Franklin and Lillian Gilbreth: Scientific management in the operating room. Quality safety health care, 18(2).

Boxwell, J. \& Robert, J. (1994), Benchmarking for competitive advantage. New York: McGraw Hill. ISBN: 0-07006899-2

Buchholz, B., Paquet, V., Punnett, L., Lee, D., \& Moir, S. (1996), PATH: A work sampling-based approach to ergonomic job analysis for construction and other non-repetitive work. Applied ergonomics, 27(3). DOI: $10.1016 / 00036870(95) 00078-X$

Campbell, J., Tutton, M. \& Pearce, J. (2014), “Staircases”, History, Repair and Conservation, Routledge Taylor \& Francis Group.

Camp, R. (1989), The search for industry best practices that lead to superior performance. Productivity Press.

Camp, R. C. (1995), Business process benchmarking: Finding and implementing best practices. American society for quality control, quality press.

Chudley, R. \& Greeno. (2006), “Advanced Construction Technology”, Pearson Education Limited.

Fifer, R. M. (1989). Cost benchmarking functions in the value chain. Strategy \& Leadership, 17(3).

Garnett, N. \& Pickrell, S. (2000), Benchmarking for construction: Theory and practice. Construction Management and Economics, 18(1).

Garnett, N. \& Pickrell, S. (1995), Construction industry benchmarking. Proceedings of school of business and industrial management conference, London, UK.

Groover, M. P. (2007), Work systems and methods, measurement, and management of work. London: Pearson education international. ISBN: 978-0-13-140650-6

Hassoun, N., Wyns, J. \& Al-Manaseer, A. (2015), "Structural Concrete”, Theory and Design, John Wiley \& Sons, Inc., Hoboken, New Jersey.

Investopedia, (2016). What is throughput?

Jiang, H., Gao, H. \& Wang, B. (2012), "Seismic damage analyses of staircases in RC frame structures", Advanced Materials Research Vols., 446-449, Trans Tech Publications.

Krenn, M. (2011), From scientific management to homemaking: Lillian M. Gilbreth's contributions to the development of management thought. Management \& Organizational History, 6(2).

Neufert, E. \& Neufert, P. (2000), “Architects’ Data”, Blackwell Science, ISBN 0-632-05771-8.

Payne, S. C., Youngcourt, S. S. \& Watrous, K. M. (2006), Portrayals o F. W. Taylor across textbooks. Journal of management history, 12(4).

Price, B. (1989), Frank and Lillian Gilbreth and the manufacture and marketing of motion study, 1908-1924. Business and economic history, 18(2).

Seeley, R. (1986), "Building Technology”, Macmillan Education Limited.

Sheth, V. (2000), Industrial engineering methods and practices. Mumbai: Penram international publishing. ISBN: 81-87972-18-1 
Tsai, W. H. (1996), A technical note on using work sampling to estimate the effort on activities under activitybased costing. International journal of production economics, 43(1). DOI: 10.1016/0925-5273(95)00189-1

Walker, A. (1996), Project management in construction benchmarking for construction. $3^{\text {rd }}$ Edition Blackwell, Oxford. 